
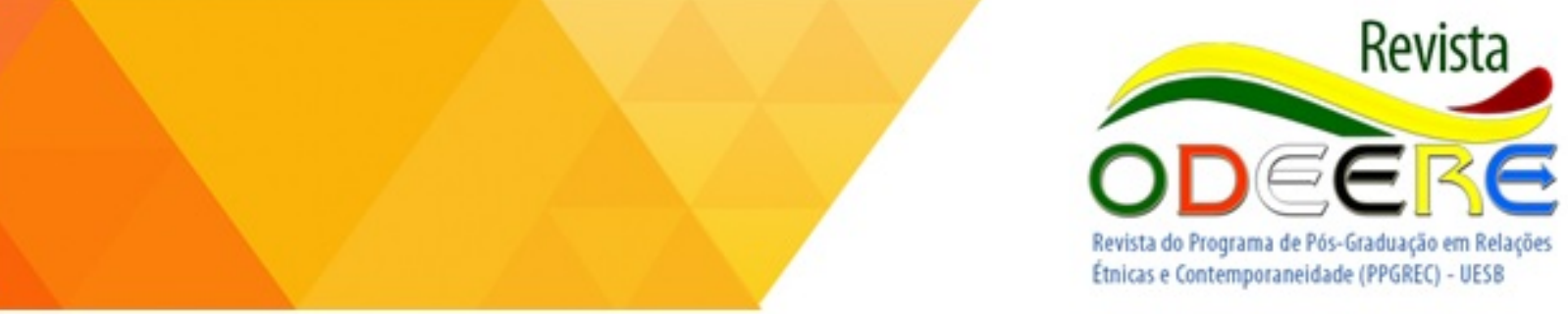

GÊNERO E ETNICIDADE: Conhecimentos de urgência em tempos de barbárie

\section{GENDER AND}

ETHNICITY:

Urgent

\section{knowledge in}

\section{barbarian times}

\author{
Mary Garcia Castro \\ Universidade Estadual do Sudoeste da \\ Bahia - Programa de Pós-Graduação em \\ Relações Étnicas e Contemporaneidade
}

(UESB-PPGREC)

DOI: https://doi.org/10.22481/odeere.v3i6.4239
RESUMO

Este artigo-ensaio discute a propriedade do chamado paradigma da complexidade conjugado ao pensamento crítico para analises relacionadas a gênero assim como aquelas que focalizam relações étnicas, em especial em tempos que se tende a verdades pautadas em 'pensamento único'. Advoga-se que há que combater simplificações sobre tais temas, questionando-se, por exemplo, a campanha que considera gênero como ideologia e etnicidade como saber orientado exclusivamente à tradição e povos originais. Ressalta-se trânsitos entre cultura, política e projetos de resistência. Contudo se adverte que tanto interdisciplinaridade como pensamento complexo, pedem ambiências institucionais abertas ao diálogo e o não abandono do disciplinar. Alem de conhecimento das doxas das disciplinas que se combinam e observação do princípio Foulcaultiano quanto à equação saber/poder. Mais se estende sobre gênero como conhecimento em aberto que vem, inclusivem sendo questionado por alguns autores pela multiplicidade performática. Insiste-se que tanto gênero e sexualidade, assim como relações étnicas pedem ênfase em teias de relações sociais e debates teóricos submetidos ao crivo de estudos etnográficos, já que comportam diversidades de realizações, vivencias e pedem nexos entre textos e contextos.

Palavras chaves: pensamento complexo; interdisciplinaridade, gênero, relações étnicas

\section{ABSTRACT}

This article discusses the property of the so-called paradigm of complexity in conjunction to the critical thinking for gender-related analyses as well as those that focus on ethnic relations. It advocates that we must combat simplifications, such as the campaign that considers gender an 
ideology and ethnicity as oriented exclusively to tradition and original people. The complexity of gender and ethnical relations asks for emphases and transits between culture, politics and projects. However it warns that both, interdisciplinarity as complex thought require institutional environments open to dialogue, and not abandonment of disciplines. In addition it is discussed the importance to combine doxas and the observation of the Foulcaultian principle on the equation knowledge/power. More extends about gender as an open knowledge that is being questioned by some authors for its relacion to performativity and the multiplicity of cases it enrolls. Gender is an open knowledge if the paradigm of complexity and a critical thinking are considered. Ethnic relations is another complex kmowledge that asks for emphases on webs of social relations and theoretical discussions submitted to ethnographic studies. Both knowledges are important to these times, against the idea of a single thought since they involve debates on diversity, political and cultural dimensions as well as forms of resistance. They are embedded in experiences and require connections between texts and contexts.

Key words: Gender, Ethnical relations, paradigm of complexity, interdisciplinary perspective.

\section{Algo sobre a intenção e Advertências}

Pretendo nesta peça apresentar reflexões sobre o nexo entre interdisciplinaridade e a formação de um conhecimento complexo, que resgate princípios do pensamento crítico e estético e que vá além da redução, da junção ou mesmo diálogo entre disciplinas, ou seja, da multidisciplinaridade, enfoque corrente mas não suficiente, em especial para o debate de conhecimentos como gênero e etnicidade. Esses alem de diálogo entre várias disciplinas e ouvidos atentos à tradição, a conhecimentos nativos, nos desafiam com a questão subjacente: que perspectiva se necessita para melhor conhecer e colaborar para o debate sobre relações étnicoraciais e de gênero, alem de crítica a preconceitos e meras tolerâncias, considerando seu apelo a culturas de resistência e atenção à alteridade?

Adianto que o desafio maior é abordar tais conhecimentos/modos de ser e viver-relações étnicas e gênero ou, segundo as francesas, relações sociais entre sexos-, através de um paradigma da complexidade, um dos eixos deste artigo.

Subjacente a tal perspectiva, a defesa da importância do chamado paradigma da complexidade, formulado originalmente por Edgard Morin ${ }^{1}$ e comentado por Eduardo Mourão Vasconcelos ${ }^{2}$, resgatando também autores como Pablo Casanova ${ }^{3}$ e Martha Nussbaum ${ }^{4}$

\footnotetext{
${ }^{1}$ MORIN, Edgar Introdução ao Pensamento Complexo, Instituto Piaget, Lisboa 1991

2 VASCONCELOS, Eduardo Mourão Complexidade e Pesquisa Interdisciplinar. Epistemologia e Metodologia Operativa, Ed Vozes, Petrópolis, 2009
} 
Esses autores contribuem para tal paradigma da complexidade, minha leitura, de vertente das ciências humanas, embasado no pensamento crítico e nas artes e mais avançam em proposta de um conhecimento político e de intervenção. Tipo de postura político cognitiva importante para estes tempos, em especial considerando a onda conservadora que vem assolando vários países e que no Brasil assume thriller de barbárie civilizacional.

Morin ${ }^{5}$ considera como paradigma da simplicidade, ou melhor da simplificação e do reducionismo do mundo, o pensamento único, que viria pautando a nova onda neoliberal, fundamentalista, o que tento também neste espaço ilustrar com debates sobre gênero, a meu juízo uma ilustração de conhecimento que pede inscrição no paradigma da complexidade. Adianto que a campanha contra a chamada "ideologia de gênero", que apela para uma educação conservadora, é ilustrativa do paradigma da simplicidade.

Com menos propriedade hoje, pois apenas engatinho no debate sobre etnicidade, ouso notas sobre esse conhecimento, que também sugere a necessidade de abordagem por perspectiva da complexidade, considerando como discutido por autores de distintas inscrições intelectuais e que por alguns, como Manuela Carneiro da Cunha ${ }^{6}$, é ressaltado como também enriquecido se objeto de ativismo político e um saber/ouvir/aprender/refletir/intervir juntos. Recusa-se portanto a bem-intencionada neocolonial orientação do "dar voz" aos subalternos, aos objetos assujeitados em pesquisas. Reconhece-se que etnicidade é conceito fluido que pede textualidade, mas principalmente contextualidade e combinação entre lugar de fala e lugar de escuta. Vários autores discutem como etnicidade teria sido usada para a defesa de interesses coloniais e sua potencialidade para visibilizar comunidades que insistem em fronteiras, por identidades próprias, inclusive na genérica "identidade nacional". Ver, por exemplo artigos em Santana, Dias Ferreira e Nascimento ${ }^{7}$.

Em "Etnicidade da cultura residual, mas irredutível" Carneiro da Cunha (op.cit.) rejeita, assim como nós rejeitamos em relação a gênero, a perspectiva de que comunidades étnicas se

\footnotetext{
${ }^{3}$ CASANOVA, Pablo As Novas Ciências e as Humanidades. Da Academia à Política. Ed Boi Tempo, São Paulo, 2006

${ }^{4}$ NUSSBAUM, Martha C. It is Not for Profit. Why Democracy needs the Humanities Princepton University Press, Princeton, 2010

${ }^{5}$ MORIN, Edgar." Por uma reforma do pensamento". In: PENA-VEGA, Alfredo, NASCIMENTO, Elimar Pinheiro do (Org.). O Pensar Complexo: Edgar Morin e a crise da modernidade. Rio de Janeiro: Garamond, 1999

${ }^{6}$ CARNEIRO DA CUNHA, Manuela Cultura com aspas e outros ensaios. UBU Editora. São Paulo, 2017

7 SANTANA, Marise; DIAS FERREIRA, Edson e NASCIMENTO, Washington Santos Etnicidades e Trânsitos. Estudos sobre Bahia e Luanda, Jequié/Ba e Rio de Janeiro/RJ, Odeere-UESB e UERJ-UFRJ, 2017
} 
resumem a demandar conhecimento pautado em ideologias, tradição e por 'vitimismos'. Advoga que essas querem ser compreendidas como uma "linguagem política", o que pede comunicação sobre percepções do mundo, leituras próprias além de epistemologias coloniais. Leituras que entrelacem o simbólico e o material, saberes sobre o tradicional, sim, mas não congelados, acoplados a necessidades, mudanças para vivencias no contemporâneo. Sublinha, em final de capítulo, Carneiro da Cunha ${ }^{8}$

Recapitularei um pouco - não será inútil, o que andei dizendo. Tentei mostrar que a etnicidade pode ser mais bem entendida se vista em situação, como uma forma de organização política; essa perspectiva tem sido muito fecunda e tem levado a considerar cultura como algo constantemente reelaborado, despojando-se, portanto, esse conceito do peso constituinte de que já fora revestido [...] etnicidade não seria uma cultura analítica, mas uma cultura 'nativa'.

Arruti ${ }^{9}$ no verbete "Etnicidade" chama atenção que para o debate sobre esse conceito há que estar atento à sua história, diversas apreensões político-territoriais como no Brasil, Portugal e África, o que estaria relacionado a sua recorrência em processos de colonialidade, assim como para a propriedade de perspectivas teóricas que o afastariam de visões essencialistas pautadas na cultura ou na natureza. Considera a importância para o debate sobre etnicidade, teorias sobre 'comunidades imaginadas' ${ }^{10}$ e as do reconhecimento e distribuição ${ }^{11}$

Não cabe aos propósitos deste artigo referência cortada do rico verbete de Arruti (op. cit.), mas nos serve sua sugestão sobre a complexidade do conceito de etnicidade, principalmente quando a ênfase são relações étnicas, e como há que entrelaçá-lo com diferentes aportes disciplinares e contextualizações para o nexo entre conceito e diversidades de realizações empíricas. O que também se dá com o conceito de gênero, que se apela para cultura e biologia

\footnotetext{
${ }^{8}$ CARNEIRO DA CUNHA, op.cit: p. 249

9 ARRUTI, José Mauricio "Etnicidade" In SANSONE, Lívio e ALVES FURTADO, Claudio (org.) Dicionário crítico das ciências sociais dos países de fala oficial portuguesa. Salvador, ABA Publicações e EDUFBA, 2014: p 199-2014

${ }^{10}$ ANDERSON, Benedict. Comunidades imaginadas: reflexões sobre a origem e a difusão do nacionalismo. São Paulo: Ática, 2008

${ }^{11}$ (ver entre outros: TAYLOR, Charles. El multiculturalismo y la política del reconocimiento. México, Fondo de Cultura Económica, 1993; HONNETH, Axel., The Struggle for Recognition. The Moral Grammar of Social Conflicts. Cambridge, MIT Press, 1995: e FRASER, Nancy "Da redistribuição ao reconhecimento? Dilemas da justiça em uma era 'pós socialista"” In Cadernos de campo, São Paulo, n. 14/15, p. 231-239, 2006. Fraser (op. cit.) mais defende a relação entre reconhecimento distribuição).
} 
não comporta essencialismos, como indica Butler ${ }^{12}$, já que sexo/gênero como performática não se encaixa em binarismos, ou determinismos quer da natureza ou da cultura; sendo conceito político e cultural, e muito mais, aproximando-se da ideia de comunidades imaginadas, construções com propósitos e referidos a uma alteridade, um outro, diferente, em situação de dominação e se pede reconhecimento também advoga direitos à distribuição.

Arruti e Heymann ${ }^{13}$ referem-se à propriedade dos debates sobre reconhecimento e distribuição quer para etnicidade quer para gênero, tendo em vista a questão de memórias específicas, o que colaboraria para mais rica e diversificada noção de cidadania e democracia, na contemporaneidade:

O que se observa, então, em linhas gerais, é a busca por reconhecimento e legitimidade por parte de grupos que, destacando-se na comunidade nacional, passam a definir-se a partir de novas categorias, sejam elas étnicas, religiosas, de gênero etc. Nesse processo, estão em jogo novas formas de auto identificação das quais decorrem as lutas por manter vivas memórias particulares, conquistando para elas espaço no discurso histórico oficial, por inclusão sem homogeneização e, finalmente, por representação política e direitos. Tal fenômeno vem provocando a rediscussão de conceitos como os de cidadania e democracia.

Etnicidade, relações étnicas e gênero são conceitos que pedem perspectiva de complexidade e atenção a cenários materiais e simbólicos quanto a diversas relações sociais, quer de conflitos quer de negociações.

Advogo, neste estágio de (re)conhecimento, que gênero e etnicidade pedem sinais diacríticos e construtos distintos e muitas vezes contraditórios, como por exemplo a ênfase dada ao passado, à tradição, em alguns usos sobre etnicidade, e a recusa da herança patriarcal em gênero e a busca por horizontes próprios, inventar futuros. Contudo tanto como a gênero atribuo, potencialidades desmistificadoras do disciplinamento de cosmovisões no debate sobre etnicidade e relações étnicas e atenção à diversidade de realizações, o que exige olhar etnográfico, pois se

\footnotetext{
12 BUTLER, Judith. "Gender as Performance: An Interview with Judith Butler." Radical Philosophy, 67, Summer 1994. Disponível em: http://www.theory.org.uk/but-int1.htm. Acesso em 14/09/2018.

${ }^{13}$ ARRUTI, José Mauricio e HEYMANN, Luciana "Memória e reconhecimento: notas sobre as disputas contemporâneas pela gestão da memória na França e no Brasil" Em http://www.academia.edu/6305947/Mem\%C3\%B3ria_e_reconhecimento_notas_sobre_as_disputas_conte mpor\%C3\%A2neas_pela_gest\%C3\%A3o_da_mem\%C3\%B3ria_na_Fran\%C3\%A7a_e_no_Brasil. 2012. Acesso em 12/09/2018
} 
são conceitos não se realizam na íntegra em casos diversos, e tais casos desafiam os limites conceituais. É o que leio em Arruti $^{14}$ :

Se o racismo permite falar da existência de um grupo por meio de atributos imputados e raramente afirmados, a etnicidade tem como maior atributo constituir o próprio grupo com base na resposta a tal imputação. Uma radicalização do caráter relacional que está na base da definição teórica dos grupos étnicos.

Assim, a etnicidade passa a descrever performances identitárias que incluem também os amplos contextos derivados da diáspora africana, assim como da reorganização em contexto urbano dos grupos étnicos e nacionais em processo de migração rural-urbana, assim como de imigração entre fronteiras nacionais. Em todos estes casos, a etnicidade continua servindo para classificar e -com base no Dicionário crítico das ciências sociais dos países de fala oficial portuguesa-[ser] classificação, organizar e regular a interação entre indivíduos, mas agora tendo por base um arco de formas sociológicas que vão do grupo étnico às comunidades imaginadas de diversos tipos.

Esta é a intenção deste artigo, uma exposição de um projeto pedagógico por ser, estudo em processo, a vir colaborar na formação de "espectadores e atores/atrizes emancipados" intelectualmente críticos, expressão de Jacques Rancière ${ }^{15}$. Tal projeto segundo Jacques Rancière exige que o mestre se considere e atue como ignorante, aprendendo junto. Então não são verdades, mas intenções que compartilho.

\section{Algo sobre interdisciplinaridade}

Contra a excessiva fragmentação do saber em disciplinas se desenvolveu um movimento, em especial a partir do início do século XX, em prol do estudo de totalidades, referidas a questões, mesmo especificas. Faz parte desse movimento a teoria da Gestalt em psicologia, preocupada com a consciência do todo. Segundo Casanova (op. cit.), seus autores advogavam que o todo não é uma soma das partes, e que focalizando o todo se chegaria a tendências e à identificação de relações. Em 1920, segundo Casanova ${ }^{16}$, "W Kohler demonstra que não se poderia explicar estruturas psicológicas por sua origem microfísica". Colaboram para tal movimento, filosofias

\footnotetext{
${ }^{14}$ Arruti (op cit: p.209):

${ }^{15}$ RANCIĖRE, Jacques O Espectador Emancipado, Ed Martins Fonte, São Paulo, 2008

${ }^{16}$ Casanova (op. cit; $p$ 19.),
} 
críticas, marxistas e historicistas assim como analíticas. Mas é em 1937 que se usa pela primeira vez a palavra "interdisciplinar", em textos do sociólogo Louis Wirtz:

Desde então se estabeleceu a necessidade de alcançar uma cultura geral que permitisse ao estudioso mudar de especialidade no curso de sua vida intelectual. Propôs-se uma solução que continua válida: tornar-se especialista no estudo de um problema, independentemente de qualquer especialização, advinda das disciplinas que se ensinam em distintas faculdades [...], considerando que os fenômenos são multidimensionais [...]. A vinculação criadora da cultura geral e da especialização se reafirmou ao longo do século $\mathrm{XX}^{17}$.

Contudo, interdisciplinaridade no saber acadêmico, há algum tempo, se converteu em um modismo que não necessariamente segue uma regra básica de tal método, qual seja que se faz necessário "aprender a aprender"- "expressão que não é meramente uma frase, mas que corresponde à necessidade cada vez maior de dominar os métodos de aprendizagem em um mundo em que o conhecimento se acumula a uma velocidade crescente e o complexo banalizado em 'achismos' ${ }^{18}$.

O quadro que segue é de exposição de Alvarenga et al $^{19}$, que no Brasil teve importante papel na estruturação da área interdisciplinar na CAPES, em 2008, a partir da área multidisciplinar criada em 1999:

\section{Quadro 1 - Características da Interdisciplinaridade}

- A Interdisciplinaridade apresenta-se nos anos 1960 como uma importante busca de respostas aos limites do conhecimento simplificador, dicotômico e disciplinar.

- Sua proposta nega o pressuposto básico do conhecimento "objetivo" do pensamento simplificador de que existe um "vazio" entre as fronteiras disciplinares, conforme assinala Kuhn (1975).

- Sublinha a necessidade das trocas entre diferentes disciplinas.

- Pede a adoção de uma nova relação sujeito observador - objeto observado no processo de conhecimento.

${ }^{17}$ (Casanova, op. cit: 20)
${ }^{18}$ (Casanova, 2006: 20),

19 ALVARENGA, Augusta Tereza; PHILIPPI JR, Arlindo; SOMMERMAN, Américo; ALVAREZ, Aparecida Magali de Souza; FERNANDEZ, Valdir. "Histórico, Fundamentos filosóficos e teóricometodológicos da interdisciplinaridade. In: PHILIPPI JR, Arlindo e SILVA NETO, Antônio J. Silva (Editores). Interdisciplinaridade em Ciência, Tecnologia e Inovação. Barueri: Manole, 2011. 
- É perspectiva influenciada pela publicação de obras com reflexões epistemológicas como a de Karl Popper, "A lógica da Investigação Científica", em 1959, na Inglaterra, que introduz o princípio da incerteza na ciência pela sua proposta não de uma "confirmação" de proposições científicas, para a verificação da verdade do conhecimento, mas de "falseabilidade" das teorias, como busca de verdades provisórias. ${ }^{20}$

Em Castro ${ }^{21}$, advertia-se para o risco de modismo de um conhecimento que no justo afã contra a fragmentação do real, poderia ser interpretado como contrário à necessidade de saber especializado e assim fragilizaria a evolução de disciplinas especificas, quando possivelmente o que mais necessitemos seja de investimento em uma epistemologia que priorizando problemas sociais, existenciais, ecológicos, políticos focalize debates pautados pela alteridade, ou seja exposições ao outro, a outra, não somente de disciplinas diferentes, mas de cosmo visões, lugares político ideológicos diferenciados, pelo exercício da dialética discursiva, o enfrentamento dialógico de idéias, e o questionamento da hierarquia burocrática que divide papeis entre alunos e professores não por conhecimento ou criatividade, mas pelo posto formal institucional e estimula competitividades, isolamentos e o não exercício da solidariedade entre pesquisadores, principal motor de um trabalho intelectual prazeroso.

Portanto, já em 2012 advogava uma epistemologia, uma postura que questionasse hegemonias ou o que Vasconcelos (op.cit.) denomina como "imperialismos epistemológicos". Não há que descuidar da equação saber/poder, o que necessariamente pede perspectiva tanto multi quanto interdisciplinar e não só entre ciências exatas, biológicas e humanas, mas também entre as humanas. Bem como o apreço pelas artes, alem do fazer pontes com conhecimentos tidos como tradicionais, como com o senso comum. Mas a construção de tal epistemologia pede muito mais. Pede reflexão crítica sobre totalidades e discutir o caminho epistemológico de cada disciplina em sua relação com um objeto foco, e principalmente, ambiência institucional de fomento ao trabalho intelectual crítico e criativo e cenários político-econômicos afins a cidadanias ativas, e uma educação emancipatória.

Uma ambiência positiva ao trabalho intelectual não necessariamente segue cânones da academia de hoje, uma ambiência mais preocupada com resultados imediatos, produtividade

\footnotetext{
${ }^{20}$ Exposição de Alvarenga, na UFBA, 2015, a partir de Alvarenga et al 2011

${ }^{21}$ CASTRO, Mary Garcia Entre a Intenção e o Gesto ou Quão Interdisciplinar Somos? Ensaio sobre a Perspectiva Interdisciplinar e Estudo de Caso sobre uma Produção de Estudos no Campo de Família In Anais do CONGRESSO INTERNACIONAL INTERDISCIPLINAR EM SOCIAIS E HUMANIDADES Niterói RJ: ANINTER-SH/ PPGSD-UFF, 03 a 06 de setembro de 2012, ISSN 2316-266X
} 
quantificada, preenchimento de relatórios e observância irrestrita de manuais e regulamentos. O livre construir de interconexões disciplinares e formatação de um conhecimento complexo são avessos a uma ambiência política, Brasil 2018, embasada em ódios, cartas marcadas no jogo institucional, fundamentalismos econômicos e religiosos e que por decreto exige que na escola se regresse sutilmente a uma orientação criacionista, recusa ao diálogo entre religiões, pede a proibição de debates sobre relações sociais de gênero e diversidade sexual, assim como estimula o apagamento do debate sobre preconceitos e discriminações étnico-raciais ${ }^{22}$

Sobre interdisciplinaridade, importante ter claro que não existe consenso sobre o que seria tal postura na produção de conhecimentos. Alinho-me a autores, como Pablo Casanova (op. cit.) e Vasconcelos (op.cit.) que consideram que o interdisciplinar é construto de um conhecimento complexo. Tais autores recusam ser o conhecimento complexo um manual de como fazer pesquisa e sim advocacia de postura ético político cientifica com pontes entre saberes. Eles sugerem que há que investir em debates teórico-ideológicos, já que interdisciplinaridade é construto de um processo de busca por um novo conhecimento, o chamado 'conhecimento complexo', quando se destaca a preocupação com totalidades, com projetos sociais, e com processos de elaboração de conhecimentos, enfatizando o legado construtivista, a exemplo dos trabalhos de Piaget e Paulo Freyre.

Coloca-se, entretanto em suspenso, o princípio que advoga Casanova de que através de caminhos interdisciplinares se chegaria, a um conhecimento complexo com um projeto emancipador. Segundo Casanova ${ }^{23}$ :

A criação do novo implica uma série de conhecimentos 'necessariamente interdisciplinares'. Supõe uma nova divisão de trabalho, uma nova divisão interdisciplinar da pesquisa, da docência e da difusão. Essa nova divisão requer a superação da disciplina sem descuidar da especialidade. Exige também a atualização da educação científica, a reformulação dos conceitos de cultura geral e o fomento à cooperação multidisciplinar, enquanto se criam e fortalecem conhecimentos interdisciplinares. (Eu sublinho.)

\footnotetext{
22 "A retirada dos planos de Educação do trecho que diz que escolas devem promover a igualdade de gênero, raça e orientação sexual foi criticada por entidades do setor educativo. Em nota pública, elas repudiam as "manifestações de intolerância e proselitismo religioso" nos processos públicos de elaboração e revisão dos planos. De acordo com essa nota, as estratégias de promoção da igualdade de gênero, raça e orientação sexual visam a dar concretude à Constituição Brasileira, à legislação educacional e às diversas normativas internacionais das quais o Brasil é signatário.As entidades defendem que a estratégia tem por objetivo superar desafios ainda presentes no Brasil como a desigualdade entre homens e mulheres em relação à renda, à formação e a presença de uma educação, sexista, homofóbica e descriminatória, entre outros. In http://www.ebc.com.br/educacao/2015/06/entidades-repudiam-retirada-da-questao-de-genero-dosplanos-de-educacao- consultado em 16.08.2017

${ }^{23}$ Casanova (op. cit: 41)
} 
Segundo Piaget: 'O problema cientifico da 'criação de novidades' significa uma nova divisão de trabalho em que um especialista registra no trabalho do outro o que lhe interessa'. Obriga a estudar as partes e o todo de um modo estrito, mas distinto. Supõe novos perigos, como ler alguns livros de maneira não linear.

De fato, a interdisciplinaridade é uma perspectiva que potencializa saltos paradigmáticos, mas depende das perguntas, dos interesses e dos tipos de saberes que são combinados. Em si não é formula mágica para novos conhecimentos, nem necessariamente um caminho para um conhecimento complexo.

A interdisciplinaridade coloca algumas questões à pratica docente e discente, como as que menciono e mais detalho a seguir:

Questão 1: interdisciplinaridade e disputas discursivas

Questão 2 - a ambiência institucional

Questão 3 - interdisciplinaridade na construção de um conhecimento complexo (transdiciplinaridade)

\subsection{Questão 1: interdisciplinaridade e disputas discursivas}

Insisto que interdisciplinaridade mais que combinar disciplinas, ou discutir um tema por diferentes olhares, e projetos políticos, sociais, é uma ferramenta para um conhecimento complexo que envolve uma disputa discursiva e um projeto cognitivo, daí sugiro outra questão para o processo de uma pratica interdisciplinar.

Discordo de autores que advogam que a interdisciplinaridade seria uma forma de conseguir equilíbrio entre saberes, 'sínteses'. Entendo que interdisciplinaridade não se constrói apenas içando pontes entre disciplinas, mas principalmente por um processo de debates entre posturas, projetos, cosmovisões, inclusive entre razão cientifica e razão teológica, e o que os pós modernos, de forma pejorativa chamam, "as grandes narrativas", como as perspectivas do materialismo cientifico sobre mudanças de sistema sócio político cultural e reconhecimento da micro política, ou vivencias nativas, o que pede estar atento a saberes do senso comum e ao imaginário que se modela pelo magico e o simbólico.

Ora, disputas discursivas não implicam necessariamente em pugilatos, extermínio do outro, mas reconhecer campos de alianças possíveis, comunalidades e colaborações, mesmo que 
relativas e estratégicas, e demarcações de fronteiras, projetos de vir a ser, códigos e estruturas, respeitando a identidade do outro conhecimento, mas principalmente por uma razão crítica do discurso disciplinar. Contribui para tal tese, a meu juízo, a reflexão de Menezes sobre Foucault ${ }^{24}$, ou seja, entender que todo saber se entrelaça com a afirmação de um poder. Cabe, portanto, recorrer a um texto não somente pelo que esse pode contribuir a um tema, mas proceder primeiro a sua exegese, à crítica, em particular dos conceitos usados. Segundo Menezes ${ }^{25}$ :

Um outro elemento que desperta o olhar do leitor é o fato de que, a rigor, em todos os textos do autor de "História da Sexualidade" (Foucault 1985), estejam reunidos os discursos derivados de múltiplas ciências do homem [sic. ], seja no uso singular que Foucault faz de alguns conceitos, seja na crítica que o autor dirige aos resultados que tais saberes esboçam nas suas investigações acerca do humano. Para o bem da clareza, tendo sob seu olhar, as figuras do louco, do perverso, do presidiário, do educando, etc., Foucault arrola os saberes que se apropriam destes objetos, a saber, psicologia, psiquiatria, medicina, psicanálise, direito, pedagogia, etc.... [...] Portanto não se trata de investigar as verdades sobre o objeto, derivadas de aplicações metodológicas determinadas por uma dada ciência, mas sim de inquirir os modos pelos quais tais ciências elaboram as verdades imputadas ao objeto mirado em suas lentes

Ora, considero que é fundamental para a busca de um trabalho interdisciplinar, a reflexão de Menezes (op. cit.), de separação entre doxa e realidades sociais, ao destacar que Foucault não se interroga se tal conhecimento serve para descrever e compreender um tipo de objeto especifico, uma realidade social dada. Recorre à arqueologia do conhecimento em foco. Caberia portando mais discutir por que conceitos, por que idealizações, por que visões de mundo, da história, se faz referência ao objeto de estudo?

Insisto, hoje, mais nos perigos da banalização, do que se entende por interdisciplinar-e.g., bricolagem de textos ou 'fisgada' de conceitos de outras áreas, desde que sirvam aos argumentos do pesquisador, que propriamente à arqueologia do conceito, investigação epistemológica quanto a estruturação de um conhecimento- e principalmente o poder difundido na doxa, em um conhecimento.

\footnotetext{
${ }^{24}$ MENEZES, Jose E.X. "Usos Foucaultianos da Categoria Família" in JACQUET, Christine e FIALHO COSTA, Lívia Família em Mudança Cia Ilimitada, São Paulo, 2004

${ }^{25}$ Menezes (op. cit.:292)
} 


\subsection{Questão 2: A ambiência institucional}

A academia cada vez é menos um lugar de debate, de disputas de ideias e mais uma fábrica de produção de mercadorias, como artigos que quando muito são apresentados e debatidos em congressos ou em uma aula, mas não entre pares de uma mesma instituição, na comunidade de pertença intelectual, a academia, a escola, que segundo Hanna Arendt, deveria ser a "casa da razão". Ora razão é debate, analisar doxas, tornar transparente e ter a capacidade democrática de estimular disputas entre saberes/poderes, friso.

Não há dialogo, disputa, debate intelectual possível em uma academia, que vem se estruturando pelo principio capitalista da competição, da produção em série, do "publique ou lhe devoro", separando cada vez mais o intelectual, o critico, o ensaísta, do acadêmico e do analista de estudos de caso. Como não há condições para o pensamento crítico em uma escola que disciplina corpos e mentes, podando a construção de sujeitos.

Sobre essa questão, que instituição permitiria uma pratica interdisciplinar, recorro, também a voo de pássaro, a Martha Nussbaum (op, cit.) sobre uma educação crítica e criativa para o exercício da autonomia e o lugar da escola ${ }^{26}$

Nussbaum (op.cit.) advoga que faltaria uma orientação educacional nas escolas que reúna perspectiva defendida por Sócrates, qual seja de formar cidadãos e cidadãs críticos, criativos e orientados para argumentar, e a filosofia educacional de Rabindranath Tagore - prêmio Nobel de Literatura em 1913 e autor de perspectiva inovadora em educação. Tagore destacava o objetivo de 'empoderamento' dos jovens por sua exposição a diversas culturas e inserção da música, belas artes, teatro e dança em todo o currículo, como linguagem expressiva de formas de ser no mundo, em que o corpo, o desejo, o afeto, os valores de solidariedade, de interesse e respeito ao outro a outra, fossem estimulados e tidos como linguagens em diversas disciplinas- o ensinar dançando, o dançar ensinando.

Recorre assim Nussbaum (op.cit.) à combinação entre humanidades e arte, apelando para Tagore, romancista, teatrólogo, filosofo e educador indiano, que fundou uma escola considerada não convencional. As aulas eram dadas ao ar livre, por debates e os currículos misturavam artes com matemáticas e ciências biológicas, entre outras. Os estudantes eram estimulados a deliberar

\footnotetext{
${ }^{26}$ Debate desenvolvido em CASTRO, Mary Garcia; REIS, Selma. E ABRANOVAY, Miriam Limites dos Conceitos de Tolerância, Vulnerabilidade e Proteção para o Debate sobre Autonomia e Homo Afetividade na Escola. In https://nugsexdiadorim.files.wordpress.com/2011/12/vulnerabilidades-protec3a7c3a3o-eautonomia-direitos-humanos-e-homo-afetividade-na-escola-difc3adceis-combinac3a7c3b5es.pdf consultado em 20.10.2018
} 
sobre o dia a dia da escola e a organizar encontros de debates. Segundo Nussbaum ${ }^{27}$ :

Tagore foi também um impressionante filosofo cujo livro 'Nacionalismo' (1917) é uma grande contribuição ao pensamento sobre o Estado moderno e que na [sua obra] 'Religião do Ser Humano' (1930) argumenta que a humanidade só pode progredir, cultivando sua capacidade para uma simpatia mais inclusiva e que tal capacidade só pode ser cultivada por uma educação que compreenda a cultura global, artes e a perspectiva Socrática de auto crítica [...] Para ele as artes seriam básicas para o desenvolvimento da personalidade (Original em inglês. Tradução própria.)

Em síntese, interdisciplinaridade pode ser uma nova prática de construção em equipe de conhecimentos, como relações étnicas e gênero e sexualidade, mas o desafio maior, insisto, é ter tal prática como um projeto em outro projeto, o de pensar a complexidade, como bem indica Casanova $^{28}$ :

A interdisciplina não é somente uma nova forma de organizar o conhecimento, mas uma busca de um novo conhecimento em prol da humanidade Exemplo- perspectiva de Paulo Freire que propõe um conhecimento que parta da vida cotidiana e da região da qual se pensa um novo conhecimento, o que pede nexos entre pesquisa ação e docência caso da alfabetização crítica".

\subsection{Questão 3 - Interdisciplinaridade na construção de um conhecimento complexo}

Seguindo a modelagem de Edgard Morin sobre o que seria um paradigma da complexidade, destaca-se a importância da crítica, da liberdade quanto a linguagens, da autonomia e da busca. Assim Almeida ${ }^{29}$, reflete sobre o pensamento de Morin:

Ninguém pode aprender por mim, no meu lugar. Esta é a face de uma autonomia cognitiva. Todos 'assunto conhecido por si só, o é em si e por si mesmo', diz Edgar Morin. A simbiose entre autonomia e dependência não está restrita ao processo de produção de conhecimento. É uma dinâmica de sistemas complexos. Então o que ele diz sobre a construção social do indivíduo, podemos dizer que o mais dependente de informações e

\footnotetext{
${ }^{27}$ Nussbaum (op. cit.: 68 ):

${ }^{28}$ Casanova (op. cit.: 46):

${ }^{29}$ ALMEIDA, Maria Conceição de Para Compreender la Complexidad, Hermosillo, Sonora, México 2008; 45
} 
situações diversas, embora mais viva e passa por vários estados do ser, mais possibilidades tende a se auto organizar em formas mais complexas e abertas Autonomia é um rosto seguido pela unidade. É sempre temporária e parcial (Original em espanhol. Tradução própria).

Outra característica do conhecimento complexo é o interesse por emergências, o epocal, o novo que encontra na linguagem artística, por ser campo não preso a métodos rígidos. Segundo Almeida $^{30}$ :

O complexo transporta, implica ou expressa emergência. O que é da ordem do dia, do evento novo e não previsível, a emergência é uma noção crucial para compreender a complexidade. O surgimento da vida foi uma emergência relacionada; uma descoberta científica é uma emergência em relação ao conhecimento já estabelecido; o surgimento de uma nova espécie (a espécie humana, por exemplo) constitui uma emergência na cadeia de evolução animal; um novo paradigma é uma emergência da história do conhecimento e assim por diante. As conversões de emergência se dão sobre uma combinação original de elementos ou normas existentes. Dito de outra forma, a emergência inaugura relações entre padrão e variação; entre o universal e o particular; entre a unidade e a diversidade. A criação artística e a singularidade do sujeito são (semelhante ao que ocorre com a matéria em geral), expressões da emergência no domínio da cultura humana. (Original em espanhol. Tradução própria.)

Em resumo, sobre o conhecimento complexo, considerando Morin destaco, a partir de Vasconcelos (op. cit.) que Morin questiona o "paradigma da simplicidade", o saber convencional, que se apega de forma acrítica à tradição, que inspira a fragmentação e o hermetismo atual das ciências e eu diria, também de ideários que se pretendem normativos, que se fixam em verdades e determinismos, fogem do novo, do emergente, e não dialogam com outros conhecimentos. Morin contrapõe esse ao que chamou "paradigma da complexidade". Segundo Vasconcelos (op. cit.) Morin entende por complexidade o que foi tecido junto; de fato, há complexidade quando elementos diferentes são inseparáveis constitutivos do todo (como o econômico, o político, o sociológico, o psicológico, o afetivo e o mitológico), e há um tecido interdependente, interativo e inter retroativo entre o objeto do conhecimento e seu contexto, as partes e o todo, as partes entre si. Por isso, a complexidade é a união entre a "unidade e a multiplicidade". "Daí, ela se

\footnotetext{
${ }^{30}$ Almeida (op. cit.; 60)
} 
apresentar com os traços inquietantes da confusão, do inextricável, da desordem, da ambiguidade e da incerteza ${ }^{31}$

\section{Gênero e relações étnico-raciais. Críticas à interseção de ordens de subalternização}

O Brasil hoje, insisto, vem enfrentando uma disputa mais que discursiva, por formas de conhecer e viver que comprometem conquistas no plano da igualdade, contra discriminações, violências em relação ao outro a outra, tido como diferente e que ameaça a ideia Arendtiana da escola como a casa da razão.

A proibição do conceito de gênero nos planos de educação se embasa no disciplinar, por dois sentidos, controlar vontades e corpos e combater um conhecimento, não laico por um pensamento único pautado no criacionismo.

O debate sobre gênero em perspectiva feminista critica à 'ordem de gênero patriarcal ${ }^{32}$ alinhada à 'dominação masculina' ${ }^{33} \mathrm{e}$ enfatiza sua intersecção, ou 'nó', para usar termo de Saffioti (op.cit.) ou 'alquimia', termo de Castro ${ }^{34}$ com outras ordens de subalternizações, como as que se pautam por desigualdades sociais de classe, etnicidade e raça. Hoje considero, por exposição aos debates sobre relações étnicas (ver nota 1) que se pode vir a enriquecer no plano de consideração da totalidade da teia de interações de ordens que sedimentam subalternizações, também acrescentar, ecos da dominação colonial e tendência à 'inferiorização' do outro e a busca por ser comunidade, de afeto, de traços que identificam em relação ao outro, em posição de dominação, linguagens comuns e projetos de resistência, como sugere o conceito de relações étnicas. Tal intersecções de ordens de exclusão ou de silenciamentos de linguagens culturais que singularizam resistências estimula uma outra epistemologia, em se fazendo, um saber em aberto que ilustra a meu juízo, a propriedade de perspectiva que aposte na construção de conhecimentos mais afins ao paradigma da complexidade.

Não há somente uma corrente no campo dos estudos de gênero e sexualidade, nem apenas um conceito de gêmerp. Inclusive muitos autores contemporâneos questionam dicotomias, como o feminino e o masculino, apostam em trânsitos, assim como questionam

\footnotetext{
${ }^{31}$ MORIN, Edgar e LE MOIGNE, Jean Louis. A Inteligência da Complexidade, Ed Petrópolis, Petrópolis, 2000; 38

${ }^{32}$ SAFFIOTI, Helleieth, Gênero, Patriarcado, Violência - Ed Perseu Abramo, São Paulo, 2004

${ }^{33}$ BourdieU, Pierre. A dominação masculina. São Paulo, Bertrand Brasil, 1999.

${ }^{34}$ CASTRO, Mary Garcia "Alquimia de Categorias Sociais na Produção de Sujeitos Políticos. Gênero, Raça, Geração e Classe entre Líderes do Sindicato de Serviço Doméstico em Salvador" Revista de Estudo Feministas, n 0, 1992
} 
noções estanques como público versos o privado, natureza versos cultura - ver entre outros Butler 35. O debate contemporâneo, por exemplo que se origina de escritos de feministas negras, como aquele sobre interseccionalidade, que advoga combinações entre classe, gênero, raça/etnicidade e geração, entre outros marcadores, pede um pensamento complexo que saia do plano do individualismo metodológico para apelar por combinação de processos sociais. Gênero é também um saber que traz um projeto emancipatório, contra violências, desigualdades sociais e discriminações de várias ordens

Já o saber que se pretende normativo que fundamentalistas e o pensamento conservador defendem estigmatiza gênero como 'ideologia de gênero', advogando princípios criacionistas, determinismos da natureza, do sexo, negando especificidades político culturais do ser ou estar homem ou ser ou estar mulher e assimetrias de poder, subordinando mulheres e os não inscritos em uma lógica heteronormativa. Perspectiva que a meu juízo estaria mais afim ao paradigma disciplinar de corpos e vontades, ao paradigma da simplificação.

Mas o debate sobre perspectivas feministas quanto a combinação de processos sociais e enfase em distintas relações sociais, em diferentes contextos, é aqui não desenvolvido e apenas referido para ilustrar como o conhecimento sobre gênero mais se aproxima a uma perspectiva própria do paradigma da complexidade. Gênero e etnicidade são saberes relacionais, modelados por relações socialmente hierarquizadas, portanto fogem de disciplinamentos rígidos, pedem teorias que se alimentem e se modifiquem na relação com práticas de vida e sistemas simbólicos, formas de significar tais práticas assim como o passado e o vir a ser.

De fato o saber sobre comunidades étnicas, relações étnico raciais, identidades e etnicidades, segundo minhas primeiras leituras, e que espero mais se enriqueçam com o contato com os e as colegas docentes e discentes do PPG em Relações Étnico Raciais na contemporaneidade (UESB) e com trabalhos sobre comunidades étnico raciais também sugere que tal saber pede enfoque interdisciplinar no plano de um conhecimento complexo, ao reportar a debates sobre cultura, poder e resistências; ao se anunciar como "saber provisório", ou "pontos de partida à pesquisa cientifica", dependente de pesquisas contextualizadas sobre experiências de vida, referidas à estrutura social e atenta a percepções, segundo o antropólogo Oliveira Cardoso, para quem:

Etnia é um conceito relacional, uma relação, as populações nacionais transformam-se em etnias apenas quando interagem com grupos minoritários, passando a ser orientadas por ideologias étnicas (ou raciais) e

\footnotetext{
${ }^{35}$ Butler, op. cit.
} 
investindo-se em identidades sociais contrastantes, marcadas por símbolos étnicos ${ }^{36}$

Também Manuela Carneiro da Cunha (op. cit.) estimula endereçar conhecimentos sobre etnicidade por paradigma da complexidade ao frisar que etnicidade "pode ser uma linguagem política"; que a "língua de um povo é um sistema simbólico que organiza sua percepção do mundo" ${ }^{37}$ que "identidade étnica [pede definição] em termos de adscrição, assim é índio quem se considera e é considerado índio" ${ }^{38}$ e que nos lembremos "o respeito que cada país deve à diversidade cultural dos povos que o compõem".

Ou seja, tanto gênero como etnicidade não são ideologias, mas estão sujeitados a construções ideológicas e são conhecimentos que pedem textualidade, debates teóricos críticos, informados em contextualidades, ativismo, pesquisas de caráter etnográfico e principalmente compromissos com uma sociedade não desigual.

\section{Fechando, ou melhor, abrindo questões}

Como sugere Casanova (op. cit.) a interdisciplinaridade poderia vir a colaborar não só na critica ao outro conhecimento, à outra disciplina, mas também às nossas referencias, considerando projetos de intervenção que mais aproximem o ser e o saber. Mas o pensar no complexo criticamente interpela a questão da educação.

Todos os autores que apostam como um vir a ser um conhecimento crítico e voltado a complexidade, relacionado a projeto emancipatório, advertem da necessidade de se apostar em uma outra educação. Segundo Almeida ${ }^{39}$ :

Ciente de que a construção de uma sociedade mais justa e igualitária só é possível através de uma compreensão nova e complexa do mundo, Morin centrou-se nos últimos anos sobre a reforma do sistema educativo. Livros como 'Os sete conhecimentos necessários para a educação do futuro', 'O bom começo de cabeça', 'A reconexão do conhecimento'e 'Educar em Los Angeles, era planetária' (em colaboração com E. R. Ciurana e R. Motta)

\footnotetext{
${ }^{36}$ OLIVEIRA CARDOSO de Roberto "Reconsiderando etnia" in Sociedade e Cultura, vol. 2, julhodezembro, 2003-p133-147, Universidade Federal de Goiás, Goiânia.; 147).

${ }^{37}$ Oliveira Cardoso (op. cit.: 242 );

${ }^{38}$ Oliveira Cardoso (op.cit.; 243)

${ }^{39}$ Almeida (op. cit.; 46):
} 
mostram seu interesse prioritário na educação. (Original em espanhol. Tradução própria).

A agenda de Edgard Morin para uma educação para a complexidade segundo Almeida ${ }^{40}$ apostaria em:

Pensar no compromisso social da educação com o destino de vários; explorar o presente, mas com o compromisso com o futuro; discutir conexões entre o fenômeno estudado e o ambiente ou contexto; aprender a dialogar com outras especialidades que não as suas; perseguir a interação entre arte, ciência e literatura; cuidar da comunicação, evitando saberes herméticos. Estes seriam os sete princípios a serem cultivados para que ciência e vida sejam interconectados.

Insisto, o paradigma da complexidade é temido pelo conhecimento conservador, normatizador, que busca disciplinar corpos, vontades, legitimar hegemonias e hierarquias por desigualdades sociais e principalmente o que mais teme, a constituição de "cidadanias insurgentes" ${ }^{41}$, jovens, contestadores e críticos e saberes rebeldes.

Lembremos que para Sócrates uma vida que 'não se auto examina, não se auto questiona não é digna de ser vivida por nenhum ser humano' (in Nussbaum, 2010 p 47). Para Nussbaum um problema é que as pessoas que não se auto questionam, são altamente influenciáveis, autoritárias e 'intolerantes' com os 'diferentes'. São cidadãos e cidadãs ideais para uma cultura política que se apoia em conformismos e subserviências. ${ }^{42}$

Mais que disputas discursivas sobre paradigmas, reitero, estes são tempos de ataques ao pensar criticamente, simplificar o complexo,emtão há que tecer junto com conhecimentos nativos, saberes que colaborem para melhor compreensão de relações étnicas, e outras, relações sociais no cotidiano entre diferentes. Ora para tanto, por mais importante que seja o estudo de autores diversos que contribuem para os estudos sobre gênero assim como sobre relações étnicas, para que esses saiam do alinhamento a simplificações, é importante ousar e co-vivenciar. Em gênero discutir vidas de diferentes mulheres e povo LGBT, por trabalhos empíricos sobre percepções e condições de vida. No caso de estudos de relações étnicas o desafio é maior,

\footnotetext{
${ }^{40}$ Almeida (op. cit.; 47)

${ }^{41}$ HOLSTON, James Cidadania Insurgente. Disjunções da Democracia e da Modernidade no Brasil. Cia das Letras, São Paulo, 2013

${ }^{42}$ Castro et al. (op.cit.)
} 
discutindo linguagens, resistências no plano de culturas singulares, inclusive "imaginadas" que façam fronteiras ou negociem com aquelas com poder hegemônico, colonial ou pós colonial, investindo no desafio de identificar a propriedade do estudo de relações étnicas na contemporaneidade, além dos assentados para comunidades ditas tradicionaism Enfrentando o desafio de considerar que toda cultura subalternizada desenvolve para sua sobrevivência e resistência formas de se configurar como uma etnicidade que, em muitos casos apela para o magico, o sagrado, o tradicional mas pode ir além de tais construtos, considerando a complexidade de ser um grupo étnico aqui e agora. Somente estudos de cunho etnográfico criativos em diálogo com o acervo teórico disponível podem contribuir para outro paradigma de estudo étnico, acercando-se de sua complexidade.

Termino compartido contribuição da arte para mais complicar o debate sobre pensamento complexo:

Se diz que na cabeça dos poetas há um parafuso a menos sendo que o mais justo seria o de ter um parafuso trocado do que a menos.

A troca de parafusos provoca nos poetas uma certa disfunção lírica. Nomearei abaixo 7 sintomas dessa disfunção lírica:

1.Aceitação da inércia para dar movimento às palavras

2. Vocação para explorar mistérios irracionais

3. Percepção de contiguidades anômalas entre verbos e substantivos

4. Gostar de fazer casamentos incestuosos entre palavras

5. Amor por seres desimportantes tanto como pelas coisas desimportantes

6. Mania de dar formato de canto às asperezas de uma pedra

7. Mania de comparecer aos próprios desencontros

Essas disfunções líricas acabam por dar mais importância aos passarinhos do que aos senadores 43

Só não concordo com o final. Se não nos preocuparmos com os senadores, vamos terminar sem os passarinhos. De fato, tanto estudos sobre gênero como aqueles sobre relações étnicas têm que estar atento às relações saber/poder e às construções de resistências e transgressões.

\section{REFERÊNCIAS}

ALMEIDA, Maria Conceição de Para Compreender la Complexidad, Hermosillo, Sonora, México 2008

ALVARENGA, Augusta Tereza; PHILIPPI JR, Arlindo; SOMMERMAN, Américo; ALVAREZ, Aparecida

${ }^{43}$ BARROS, Manuel de "A Disfunção", Tratado Geral das grandezas do infinito Rio de Janeiro Record, 2001 
Magali de Souza; FERNANDEZ, Valdir. "Histórico, Fundamentos filosóficos e teórico-metodológicos da interdisciplinaridade. In: PHILIPPI JR, Arlindo e SILVA NETO, Antônio J. Silva (Editores). Interdisciplinaridade em Ciência, Tecnologia e Inovação. Barueri: Manole, 2011.

ANDERSON, Benedict. Comunidades imaginadas: reflexões sobre a origem e a difusão do nacionalismo. São Paulo: Ática, 2008

ARRUTI, José Mauricio "Etnicidade" In SANSONE, Lívio e ALVES FURTADO, Claudio (org.) Dicionário crítico das ciências sociais dos países de fala oficial portuguesa. Salvador, ABA Publicações e EDUFBA, 2014: p 199-2014

ARRUTI, José Mauricio e HEYMANN, Luciana "Memória e reconhecimento: notas sobre as disputas contemporâneas pela gestão da memória na França e no Brasil" Em http://www.academia.edu/6305947/Mem\%C3\%B3ria e reconhecimento notas sobre as disput as contempor\%C3\%A2neas pela gest\%C3\%A3o da mem\%C3\%B3ria na Fran\%C3\%A7a e no B rasil. 2012. Acesso em 12/09/2018

BARROS, Manuel de "A Disfunção", Tratado Geral das grandezas do infinito Rio de Janeiro Record, 2001

BOURDIEU, Pierre. A dominação masculina. São Paulo, Bertrand Brasil, 1999.

BUTLER, Judith. "Gender as Performance: An Interview with Judith Butler." Radical Philosophy, 67, Summer 1994. Disponível em: http://www.theory.org.uk/but-int1.htm. Acesso em 14/09/2018. CARNEIRO DA CUNHA, Manuela Cultura com aspas e outros ensaios. UBU Editora. São Paulo, 2017

CASANOVA, Pablo As Novas Ciências e as Humanidades. Da Academia à Política. Ed Boi Tempo, São Paulo, 2006

CASTRO, Mary Garcia "Alquimia de Categorias Sociais na Produção de Sujeitos Políticos. Gênero, Raça, Geração e Classe entre Líderes do Sindicato de Serviço Doméstico em Salvador" Revista de Estudo Feministas, n 0, 1992

CASTRO, Mary Garcia Entre a Intenção e o Gesto ou Quão Interdisciplinar Somos? Ensaio sobre a Perspectiva Interdisciplinar e Estudo de Caso sobre uma Produção de Estudos no Campo de Família In Anais do CONGRESSO INTERNACIONAL INTERDISCIPLINAR EM SOCIAIS E HUMANIDADES Niterói RJ: ANINTER-SH/ PPGSD-UFF, 03 a 06 de setembro de 2012, ISSN 2316-266X CASTRO, Mary Garcia; REIS, Selma. E ABRANOVAY, Miriam Limites dos Conceitos de Tolerância, Vulnerabilidade e Proteção para o Debate sobre Autonomia e Homo Afetividade na Escola. In https://nugsexdiadorim.files.wordpress.com/2011/12/vulnerabilidades-protec3a7c3a3o-eautonomia-direitos-humanos-e-homo-afetividade-na-escola-difc3adceis-combinac3a7c3b5es.pdf FRASER, Nancy "Da redistribuição ao reconhecimento? Dilemas da justiça em uma era 'pós socialista'” In Cadernos de campo, São Paulo, n. 14/15, p. 231-239, 2006.

HOLSTON, James Cidadania Insurgente. Disjunções da Democracia e da Modernidade no Brasil. Cia das Letras, São Paulo, 2013

HONNETH, Axel. , The Struggle for Recognition. The Moral Grammar of Social Conflicts. Cambridge, MIT Press, 1995.

MENEZES, Jose E.X. " "Usos Foucaultianos da Categoria Família" in JACQUET, Christine e FIALHO COSTA, Lívia Família em Mudança Cia Ilimitada, São Paulo, 2004

MORIN, Edgar Introdução ao Pensamento Complexo, Instituto Piaget, Lisboa 1991

MORIN, Edgar." Por uma reforma do pensamento". In: PENA-VEGA, Alfredo, NASCIMENTO, Elimar 
Pinheiro do (Org.). O Pensar Complexo: Edgar Morin e a crise da modernidade. Rio de Janeiro: Garamond, 1999

MORIN, Edgar e LE MOIGNE, Jean Louis. A Inteligência da Complexidade, Ed Petrópolis, Petrópolis, 2000

NUSSBAUM, Martha C. It is Not for Profit. Why Democracy needs the Humanities Princepton University Press, Princeton, 2010

OLIVEIRA CARDOSO de, Roberto "Reconsiderando etnia" in Sociedade e Cultura, vol. 2, julhodezembro, 2003-p133-147,Universidade Federal de Goiás, Goiânia.

RANCIÈRE, Jacques O Espectador Emancipado, Ed Martins Fonte, São Paulo, 2008

SANTANA, Marise; DIAS FERREIRA, Edson e NASCIMENTO, Washington Santos Etnicidades e

Trânsitos. Estudos sobre Bahia e Luanda, Jequié/Ba e Rio de Janeiro/RJ, Odeere-UESB e UERJUFRJ, 217

SAFFIOTI, Helleieth, Gênero, Patriarcado, Violência - Ed Perseu Abramo, São Paulo, 2004

TAYLOR, Charles. El multiculturalismo y "la política Del reconocimiento: ensayo de Charles Taylor. Traducción Mónica Utrilla de Neira. México, Fondo de Cultura Económica, 1993.

VASCONCELOS, Eduardo Mourão Complexidade e Pesquisa Interdisciplinar. Epistemologia e Metodologia Operativa, Ed Vozes, Petrópolis, 2009

Mary Garcia Castro: Possui graduação em Ciencias Sociais pela Universidade Federal da Bahia (1968), mestrado em Sociologia da Cultura pela Universidade Federal da Bahia (1970), mestrado em Planejamento Urbano e Regional pela Universidade Federal do Rio de Janeiro (1979) e doutorado em Sociologia - University of Florida (1989). Foi pesquisadora visitante no Centro de Estudos Porto-riquenhos do Hunter College, New York (2003-2006); bolsista da Rockefeller Foundation para estudos de pós doutorado na Universidade de Campinas (2008); e professora pesquisadora da Universidade Católica de Salvador-Mestrado e Doutorado em Família na Sociedade Contemporânea e Mestrado e Doutorado no Programa de Mestrado em Politicas Sociais e Cidadania e Co-Coordenadora do Grupo Nucleo de Estudos e Pesquisas de Juventudes, Identidade, Cidadania e Cultura-NPEJI, credenciado junto ao CNPq, na UCSAL (2004-2017/1), bolsista da FAPERJ (2010 - 2012). Foi pesquisadora CNPq com bolsa produtividade .2010-2013). Aposentada da Universidade Federal da Bahia; É bolsista de pos graduação senior na UESBPrograma de Pos Graduação em Relações Étnicas na Contemporaneidade-campus Jequié (BA); pesquisadora da Facultad Latino Americana de Ciencias Sociales (FLACSO-Brasil). e Membro da Comissão Cientifica da FLACSO-Brasil. Foi membro da Comissão Nacional de População e Desenvolvimento entre 2001-2010; participou da Global Comission of Migration, junto a ONU, (2008-2009). Foi membro do Conselho Estadual de Cultura do Estado da Bahia (12.2011 a 12.2013). Foi de 2006-2010 consultora da RITLA-Rede Iberoamericana de Tecnologia da Informação. Foi membro do Conselho Nacional de Juventude e do Conselho Nacional de Direitos da Mulher até 2007. Tem experiência na área de Sociologia, Estudos Culturais e Demografia, atuando principalmente nos seguintes temas: juventude, etnicidade e raça; migrações internacionais, genero, família, mulher, feminismo, identidades e cidadanias, modernidade e metodologia de pesquisa.

Artigo recebido para publicação em: Setembro de 2018.

Artigo aprovado para publicação em: Outubro de 2018. 